\title{
Dopamine regulation of social choice in a monogamous rodent species
}

\author{
Brandon J. Aragona ${ }^{1 *}$ and Zuoxin Wang ${ }^{2}$ \\ 1 Department of Psychology and Program in Neuroscience, University of Michigan, Ann Arbor, MI, USA \\ 2 Department of Psychology and Program in Neuroscience, Florida State University, Tallahassee, FL, USA
}

Edited by:

Paul Phillips,

University of Washington, USA

\section{Reviewed by:}

Larry J. Young, Yerkes National Primate

Research Center, USA; Emory

University School of Medicine, USA

Jeansok J. Kim,

University of Washington, USA

Scott A. Huettel, Duke University, USA

*Correspondence:

Brandon J. Aragona, Department of

Psychology and Program in

Neuroscience, University of Michigan,

530 Church Street, Ann Arbor,

MI 48109, USA

e-mail: aragona@umich.edu
There is growing appreciation that social decision making in humans is strongly influenced by hedonic and emotional processing. The field of social neuroeconomics has shown that neural systems important for reward are associated with social choice and social preferences in humans. Here, we show that the neurobiology of social preferences in a monogamous rodent species, the prairie vole, is also regulated by neural systems involved in reward and emotional processing. Specifically, we describe how mesolimbic dopamine transmission differentially mediates the formation and maintenance of monogamous pair bonds in this species. Thus, reward processing exerts tremendous regulation over social choice behaviors that serve as the foundation of a rather complex social organization. We conclude that prairie voles are an excellent model system for the neuroscience of social choice and that complex social decisionmaking can be robustly explained by reward and hedonic processing.

Keywords: nucleus accumbens, prairie vole, monogamy, social attachment, pair bond, social decision making, social neuroeconomics

\section{INTRODUCTION}

In social contexts, decision-making is significantly influenced by positive or negative concern for the welfare of others (Fehr and Camerer, 2007). Humans display strong social preferences that are revealed through choice behavior in which people behave altruistically, act on a strong sense of fairness, and have tremendous capacities to trust (Krueger et al., 2007; Sanfey, 2007; Tankersley et al., 2007; Zak et al., 2004). Indeed, social decision-making in humans is so complex that it can appear to be the result of social cognition that is exclusive to our species (Skuse and Gallagher, 2009). However, from an evolutionary perspective, pro-social behaviors such as cooperation and trust are only ostensibly irrational or selfless (Rilling et al., 2002; Sanfey, 2007). Such behaviors are the result of selection processes that favored reciprocity among close social groups, in which it was adaptive for individuals to spend relatively small amounts of energy to help unrelated members of the group in order to receive relatively large benefits of the resulting social organization (Pfeiffer et al., 2005; Rutte and Taborsky, 2007; Trivers, 1971). From this perspective, we can expect analogous pro-social behaviors to be expressed by other species that can serve as effective laboratory models and thus allow the investigation of the neural mechanisms of social choice behavior and decision-making.

Here, we describe how the use of one such model system, the socially monogamous prairie vole (Microtus ochrogaster), has significantly advanced our understanding of the neural regulation of social choice behavior (Carter et al., 1995; Dewsbury, 1987; Getz and Carter, 1996; Young and Wang, 2004). We first provide a brief overview of prairie vole behavior and suggest that the complex social organization of this species can be largely achieved by two 'choice' behaviors: the initial preference of a familiar mate and the decision to avoid or aggressively reject potentially new mates (Carter and Getz, 1993; Getz and Hofmann, 1986; Insel and Young, 2001). We then highlight data from several recent studies that describe the regulation of prairie vole social behavior by neural transmission important for emotion and reward processing, dopamine (DA) signaling within the nucleus accumbens (NAc) (Aragona and Wang, 2007; Aragona et al., 2003, 2006). Finally, we compare these findings to studies that have examined the neural regulation of social decision-making in humans (Fisher et al., 2005; Kosfeld et al., 2005; Rilling et al., 2002). These comparisons reveal striking similarities between the neuroscience of social choice behaviors between humans and prairie voles, suggesting that prairie voles are an excellent model system for the study of social decision-making. Moreover, the fact that a rather large extent of the social organization of prairie voles can be largely explained by rather simple choice behaviors regulated by emotional processing may have very interesting implications for the study of social neuroeconomics (Cacioppo et al., 2000; Lee, 2008).

\section{THE PRAIRIE VOLE MODEL}

Prairie voles are small rodents ( $\sim 40 \mathrm{~g})$ (Figure 1A) distributed primarily in the grasslands of the central United States (Cushing et al., 2001; Hall, 1981; Hoffmann and Koeppl, 1985). These rodents are among the minority of mammalian species (3-5\%) that show a monogamous social organization (Dewsbury, 1987). The foundation of this social organization is the 'pair bond', which is defined as the stable relationship between members of a breeder pair that share common territory and parental duties (Aragona and Wang, 2004). This species was initially identified as monogamous by field studies which showed that male-female pairs travel together (Getz et al., 1981), share a nest with one or more litters of pups (Getz and Hofmann, 1986), and aggressively repel unrelated intruders from 


\section{A}

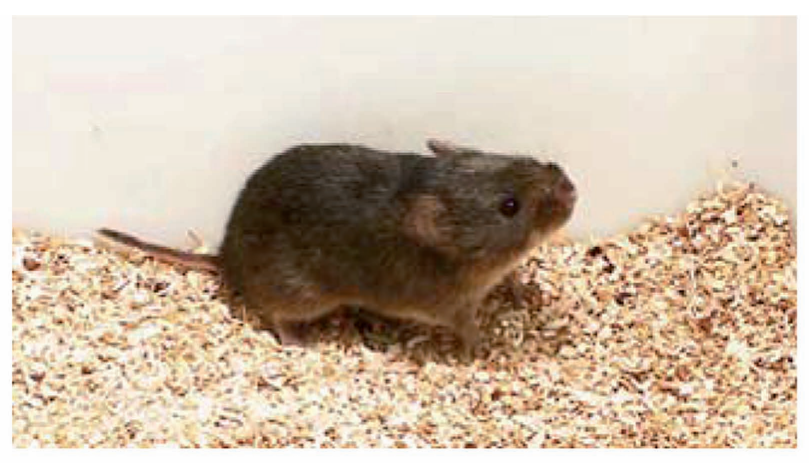

B

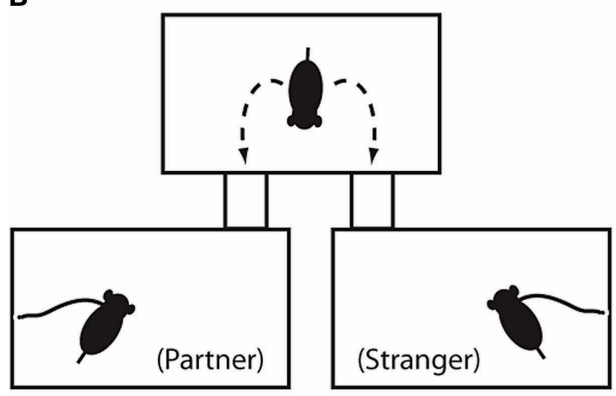

Partner Preference Apparatus c

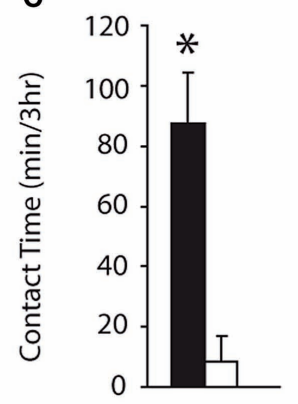

$24 \mathrm{~h} \mathrm{w} /$ mating
D

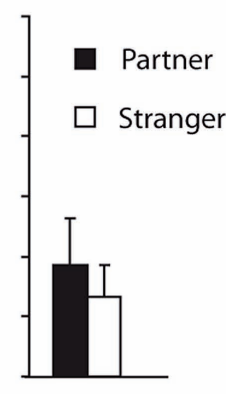

6 h cohabitation
FIGURE 1 |The prairie vole model. (A) Photo of an adult male prairie vole. (B) Cartoon of partner preference apparatus. Each cages is identical and food and water are available ad libitum throughout the 3-h test. (C) Male prairie voles paired with an estrogen-primed female for $24 \mathrm{~h}$ show a robust partner preference, i.e. spend significantly more time in side-by-side contact with their familiar mates (partners) compared to novel females that are also estrogen primed (strangers). (D) Male prairie voles paired with an ovariectomized female that is not estrogen primed for only $6 \mathrm{~h}$ do not show partner preferences; i.e. they display non-selective side-by-side contact. Error bars = standard error and * indicates groups are significantly different as determined by a $t$-test. their territory (Getz, 1978). Further, male prairie voles show high levels of parental care (Getz and Carter, 1996; Thomas and Birney, 1979) and it has been suggested that both parents are necessary for pup survival which selected for highly enduring pair bonds (Emlen and Oring, 1977; Kleiman, 1977; McGuire et al., 1993; Wang and Novak, 1992). Indeed, the pair bond is so stable that a surviving member of the pair will not accept a new mate even if the other member of the bond is lost (Getz and Carter, 1996; Thomas and Wolff, 2004). This represents a strong example of behavior that is not in the self-interest of the animal and is therefore in conflict with classic economic models of rational decision-making.

Importantly, the monogamous behaviors observed in nature are also reliably expressed under laboratory conditions (Carter and Getz, 1993; Carter et al., 1995). For instance, prairie voles preferentially mate with a familiar partner versus a novel conspecific (Dewsbury, 1975, 1987; Gray and Dewsbury, 1973). After mating, prairie voles remain together during gestation (McGuire and Novak, 1984; Thomas and Birney, 1979) and this facilitates a successful pregnancy (McGuire et al., 1992). As in their natural environment, male prairie voles show very high levels of parental care in the lab (Oliveras and Novak, 1986). Most importantly, pair bonding can be reliably assessed in the lab by measuring social preferences inferred from choice behaviors associated with the formation and maintenance of the pair bond (Williams et al., 1992; Winslow et al., 1993; Young and Wang, 2004).

\section{LABORATORY TESTS OF PAIR BOND FORMATION AND MAINTENANCE}

This review will focus on data collected from male subjects (Aragona and Wang, 2007; Aragona et al., 2003, 2006). However, there has been extensive work conducted on female prairie voles (Cho et al., 1999; Fowler et al., 2002; Insel and Hulihan, 1995; Williams et al., 1992; Witt et al., 1991) and it will be noted when data were collected using female subjects. A necessary first step in pair bond formation is that males must prefer their familiar partner over new mates, which is very unusual for males in most mammalian species since they reliably prefer to mate with novel females (Fiorino et al., 1997). However, male prairie voles prefer to mate with a familiar female (Dewsbury, 1987) and the presentation of new females does not induce copulation in sexually satiated male prairie voles (Gray and Dewsbury, 1973).

In addition to choosing to mate with a familiar female, pair bonding also requires that males choose to cohabitate with their familiar partners. This is determined in the lab by a simple social choice test referred to as the 'partner preference test' (Williams et al., 1992). For this test, a subject is placed into a three-chambered apparatus and is free to move about the chambers (Figure 1B). The familiar mate (partner) and an unfamiliar female (stranger) serve as stimulus animals that are tethered in separate cages (Figure 1B). Subjects initially explore the apparatus and interact with both stimulus animals and then lay down beside either the partner or the 
stranger (Williams et al., 1992; Winslow et al., 1993). If subjects spend significantly more time in side-by-side contact with partners over strangers (assessed by a $t$-test) then the group is said to show a partner preference (Aragona and Wang, 2004; Curtis and Wang, 2005; Liu et al., 2001).

Many studies have demonstrated that male prairie voles paired with an estrogen-primed female for $24 \mathrm{~h}$ of mating reliably show partner preferences (Aragona et al., 2003; Lim and Young, 2004; Liu et al., 2001) (Figure 1C). However, if male subjects cohabitate with females for only $6 \mathrm{~h}$ without mating, subjects show non-selective side-by-side contact and thus fail to show partner preferences (Aragona and Wang, 2007; Curtis and Wang, 2005; Liu et al., 2001) (Figure 1D). Thus, we utilize the ' $24 \mathrm{~h}$ mating' paradigm to reliably induce partner preferences in control conditions and examine if pharmacological manipulations can prevent mating-induced pair bond formation. Additionally, we use the ' 6 -h cohabitation' paradigm to examine if pharmacological manipulations can induce partner preferences in the absence of mating (Wang and Aragona, 2004; Young and Wang, 2004).

While a partner preference is necessary for a pair bond, it is not sufficient for its long-term maintenance. Pair bonded males also choose to aggressively reject potentially new mates (Aragona et al., 2006; Gobrogge et al., 2007). This is referred to as 'selective aggression' and is studied in the lab using a resident-intruder test in which the subject is exposed to novel conspecifics and aggressive behavior is quantified (Wang et al., 1997; Winslow et al., 1993). While $24 \mathrm{~h}$ of mating increases selective aggression (Wang et al., 1997; Winslow et al., 1993), aggressive behavior is increased much more toward male intruders (compared to novel females) and male subjects do not chase or bite female intruders following $24 \mathrm{~h}$ of mating (Wang et al., 1997). Conversely, following an extended cohabitation ( 2 weeks) in which females become pregnant, males become extremely aggressive toward novel females (showing high levels of chasing and biting) (Aragona et al., 2006; Gobrogge et al., 2007) and this decision to aggressively reject potentially new mates is critical for the stable maintenance of the pair bond.

In this review, we will consider the extent to which the monogamous social organization of prairie voles can be explained by (1) the initial choice to breed with a single female, the 'partner preference' and (2) the subsequent choice to reject potential new mates, selective aggression. Having these well-established laboratory indices allows detailed examination of the neurobiology underlying these behaviors. As pair bonding involves a myriad of cognitive and psychological processes, it is not surprising that a wide range of neural systems are important for its regulation including: oxytocin (Bales et al., 2007; Bamshad et al., 1993; Insel and Shapiro, 1992; Liu and Wang, 2003; Witt et al., 1990), vasopressin (Bamshad et al., 1994; Hammock and Young, 2005; Lim et al., 2004b; Liu et al., 2001; Winslow et al., 1993), corticosterone (DeVries et al., 1995, 1996; Lim et al., 2007), estrogen (Cushing and Wynne-Edwards, 2006), glutamate and GABA (Curtis and Wang, 2005). This list will certainly grow as more experiments are conducted and almost nothing is known about how these systems interact to regulate pair bonding. Thus, an extraordinary amount of work remains. However, we have recently conducted a series of studies demonstrating the significant involvement of mesolimbic DA transmission in pair bond formation and maintenance in male prairie voles (Aragona and Wang, 2007; Aragona et al., 2003, 2006).

\section{NUCLEUS ACCUMBENS DOPAMINE AND PAIR BOND FORMATION}

Pair bond formation is a naturally occurring association formed between monogamous mates (Aragona et al., 2006; Wang and Aragona, 2004; Young and Wang, 2004) and associative learning is significantly regulated by mesolimbic DA transmission (Di Chiara and Bassareo, 2007; Kelley, 2004; Wise, 2004). In particular, DA transmission within the NAc is critical for important aspects of reward processing (Berridge and Robinson, 2003; Everitt and Robbins, 2005; Roitman et al., 2005, 2008; Salamone and Correa, 2002; Wheeler et al., 2008) that may underlie cost-benefit analyses related to choice behavior and decision-making (Phillips et al., 2007). Therefore, we conducted a series of studies that investigated the regulation of partner preference formation by DA transmission within the NAc (Aragona and Wang, 2007; Aragona et al., 2003, 2006).

Similar to other rodent species (Jansson et al., 1999), prairie vole NAc is densely innervated by dopaminergic terminals arising from the ventral midbrain (Figure 2A) (Aragona et al., 2003; Curtis and Wang, 2005; Gobrogge et al., 2007). Also consistent with studies conducted in rats (Becker et al., 2001; Pfaus et al., 1995; Robinson et al., 2002), microdialysis measures indicate that mating increases extracellular DA concentration within the NAc of female prairie voles (Gingrich et al., 2000) and tissue extraction studies show that mating also increases dopamine transmission (as indicated by dopamine turnover) in male prairie voles (Figure 2B) (Aragona et al., 2003). These studies suggest that mating evokes modest increases in DA concentration within the NAc during copulation in prairie voles.

We hypothesized that mating-evoked increases in DA transmission were necessary for partner preference formation (Aragona et al., 2003). To test this, we first examined if blockade of DA receptors within the NAc prevented mating-induced partner preferences (Figure 2C). Consistent with previous studies (Williams et al., 1992; Winslow et al., 1993), control animals that received microinfusions of artificial cerebrospinal fluid (CSF) within the NAc prior to the 24-h cohabitation period (with mating) showed robust mating-induced partner preferences (Figure 2C). However, blockade of DA receptors with the non-selective DA receptor antagonist (haloperidol) prior to the mating period, abolished mating-induced partner preference formation (Figure 2C). Importantly, DA receptor blockade did not alter locomotor activity or mating behavior, indicating that DA transmission within the NAc during mating directly influenced social choice that was a consequence of mating (Aragona et al., 2003).

We next tested if pharmacological activation of DA receptors within the NAc was sufficient to induce partner preference formation in the absence of mating (Aragona et al., 2003). As previously described (Williams et al., 1992; Winslow et al., 1993), control subjects that received CSF infusions into the NAc prior to the 6-h cohabitation period did not show partner preferences (Figure 2D). However, low dose infusion of the non-selective DA agonist (apomorphine) induced a significant partner preference, whereas high dose infusion of apomorphine did not (Figure 2D). These data 


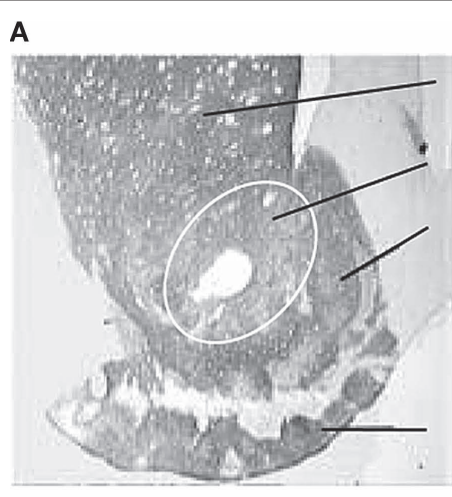

$\mathrm{CP}$

NAc core

NAc shell

Tyrosine Hydroxylase

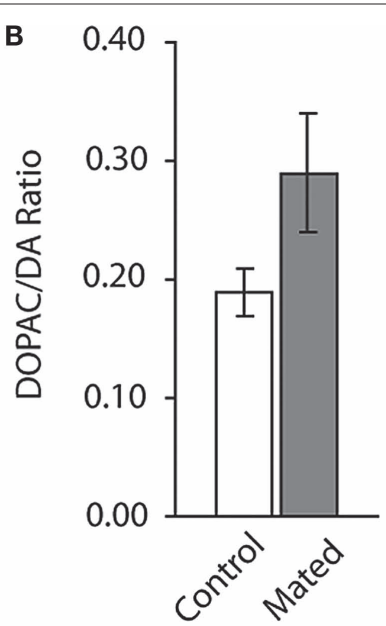

D

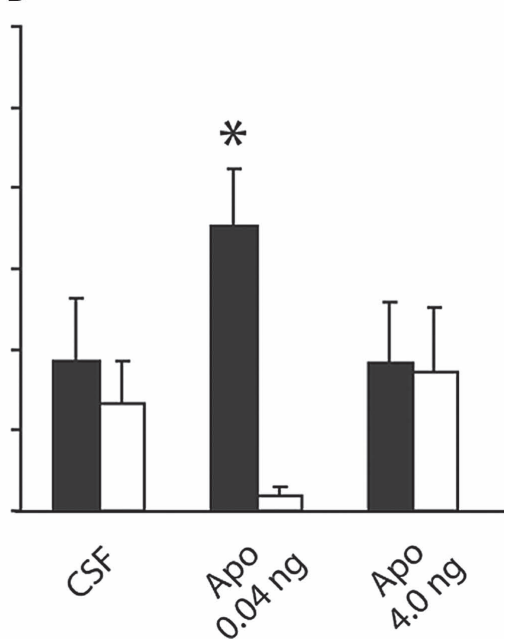

FIGURE 2 | Dopamine regulation of pair bond formation. (A) Coronal section showing tyrosine hydroxylase immunocytochemical labeling of dorsal and ventral striatum from an adult male prairie vole. $\mathrm{CP}=$ caudate putamen, $\mathrm{NAc}=$ nucleus accumbens NAc shell, OT = olfactory tuberacle. (B) Dopamine turnover as indicated by increased concentration of the dopamine metabolite DOPAC and decreased concentration of DA from micro-dissected of NAc tissue, show that pharmacological activation of DA receptors within the NAc is sufficient to facilitate choice of familiar partners.

\section{OPPOSING REGULATION OF PAIR BOND FORMATION BY D1 AND D2 RECEPTOR SIGNALING PATHWAYS IN THE NAc SHELL}

Facilitation of partner preferences by low dose apomorphine is indicative of the receptor specific mechanism underlying DA regulation of this behavior. There are two families of DA receptors: D1-like (D1 and D5 receptors) and D2-like (D2, D3, and D4 receptors) (Neve et al., 2004). While apomorphine binds both D1 and D2-like receptors, it binds D2-like receptors with a much greater affinity (Missale et al., 1998). Thus, we hypothesized that low dose apomorphine preferentially activated D2- but not D1like receptors and therefore induced partner preference formation via a D2-mediated mechanism in male prairie voles (Aragona chemical extraction, and measurement using HPLC-ED. Male prairie voles show increased mean DA turnover 30 min after mating onset with an estrogen-primed female. (C) Blockade of DA receptors within the NAc by micro-infusion of haloperidol (Halo) prevented mating-induced partner preference formation. (D) Micro-infusion of low (0.04 ng) but not high (4.0 ng) dose of apomorphine (Apo) induced partner preferences in the absence of mating. et al., 2006). Additionally, the failure of high dose apomorphine to induce partner preferences suggests that activation of D1-like receptors within the NAc actually prevents pair bond formation. These hypotheses were evaluated by testing the effects of receptor specific dopaminergic drugs on our two established paradigms to examine partner preference formation.

Consistent with data from female prairie voles (Gingrich et al., 2000; Wang et al., 1999), specific activation of D2-like receptors within the NAc shell (but not the NAc core) induced partner preferences in the absence of mating (Figure 3A). Activation of D1-like receptors within the NAc shell not only failed to induce partner preferences, but also prevented partner preferences induced by D2-like activation (i.e. when D1 and D2 agonists were co-infused) (Figure 3A). Importantly, D1-like activation within the NAc shell also blocked mating-induced partner preferences (Figure 3B). Together, these data demonstrate that activation of 


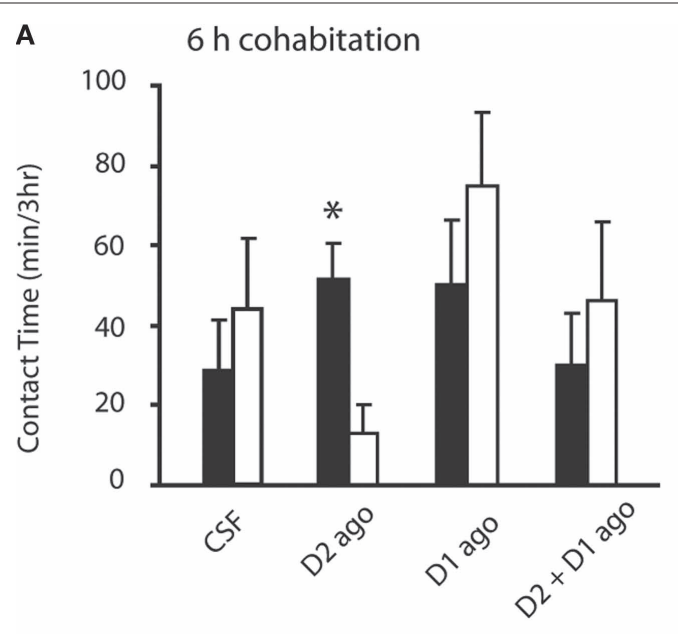

B 24 h mating

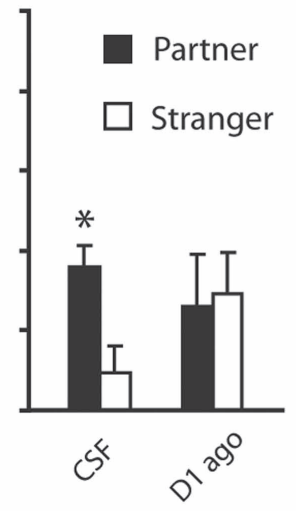

C

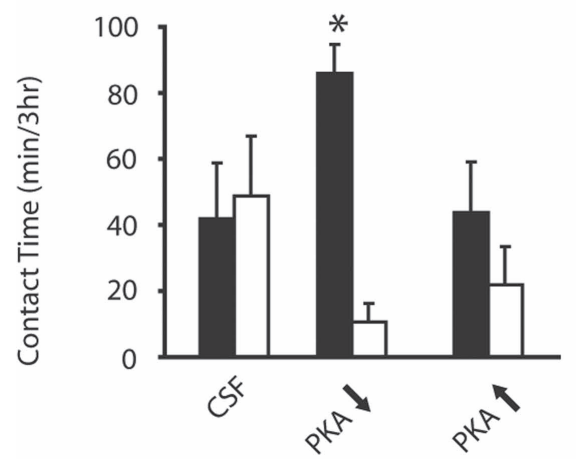

D $24 \mathrm{~h}$ mating

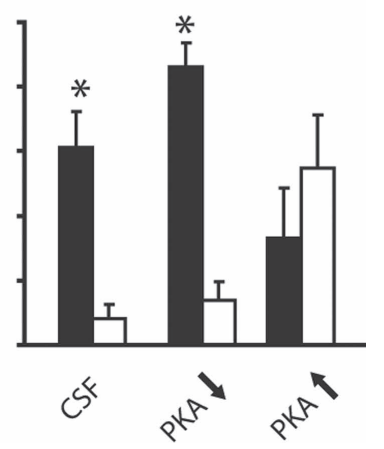

FIGURE 3 | Opposing regulation of pair bond formation by D2- and D1-like dopamine signaling systems within the NAc shell. (A) Activation of D2-like receptors within the NAc shell by micro-infusion of the D2-specific agonist quinpirole (D2 ago) induced partner preferences in the absence of mating. Activation of D1-like receptors within the shell using the D1-specific agonist SKF 38393 (D1 ago) failed to induced partner preference formation and prevented quinpirole-induced partner preferences. (B) Activation of D1-like receptors also prevented partner preferences induced by mating. (C) Decreased activation of protein kinase A (PKA) using Rp-cAMPS (PKA $\downarrow$ ) induced partner preferences in the absence of mating, whereas activation of PKA using Sp-cAMPS (PKA $\uparrow$ ) did not. (D) While decreased activation of PKA using Rp-cAMPS (PKA $\downarrow$ ) did not interfere with mating-induced partner preference formation, activation of PKA using Sp-cAMPS (PKA $\uparrow$ ) interfered with this behavior.
D1-like receptors within the NAc shell prevents the formation of partner preferences.

D1 and D2-like receptors have the opposite effects over cAMP signaling (Neve et al., 2004). D2-like receptors activate inhibitory G-proteins which prevents conversion of ATP to cAMP by adenyl cyclase (Missale et al., 1998). Conversely, activation of D1like receptors activates stimulatory G-proteins which increases cAMP production and thus activation of protein kinase A (PKA) (Missale et al., 1998). Decreased cAMP production can be studied by pharmacological blockade of cAMP binding sites on PKA using a cAMP analogue (Rp-cAMPS) whereas increased cAMP production is assessed using a cAMP analogue that binds PKA and releases its regulatory subunits (Sp-cAMPS) (Lynch and Taylor, 2005; Self et al., 1998).

Given that D2-like activation within the NAc shell mediates partner preference formation, we hypothesized that reduced PKA activity would also facilitate this behavior. Consistent with D2 regulation of pair bond formation, decreasing the activity of PKA (using Rp-cAMPS) induced partner preferences in the absence of mating (Figure 3C). Conversely, increasing activation of PKA (using Sp-cAMPS) failed to induce partner preferences (Figure 3C). As expected, decreased PKA activity did not alter mating-induced pair bond formation (Figure 3D). However, consistent with D1-like activation preventing pair bond formation, increased activation of PKA prevented mating-induced pair bond formation (Figure 3D). Together, these data indicate that pair bond formation is facilitated by D2-like activation and subsequent decreased activity of the cAMP-signaling pathway. Conversely, D1-like activation and subsequent increased activation of PKA prevent pair bond formation.

\section{UP-REGULATION OF D1-LIKE DA RECEPTORS WITHIN THE NAc OF PAIR BONDED ANIMALS}

There are dramatic behavioral alterations as male prairie voles transition from sexually naive to fully pair bonded (Carter et al., 1995). Specifically, sexually naive males primarily show pro-social behaviors toward novel females, whereas pair bonded males avoid or 
attack novel females. Given the significant role of DA transmission within the NAc in partner preference formation, we expected that alterations in this DA signaling system were associated with behavioral alterations associated with pair bonding (Aragona et al., 2006). We used receptor autoradiography to compare DA receptor density between sexually naive male prairie voles and males that were paired with a female for 2 weeks. During this extended cohabitation males and females shared a nest and the females became pregnant (Aragona et al., 2006). Representative examples of receptor binding clearly demonstrate that D1-like receptors (Figure 4A) but not D2-like receptors (Figure 4B) are substantially increased within the NAc in pair bonded males. Quantitative data show that D1like receptor binding was significantly increased within the NAc in pair bonded males compared to that of sibling-paired controls (Figure 4C). A separate control group showed that mating alone was not sufficient to increase D1-like receptor binding (Aragona et al., 2006). Thus, pair bonded animals have an enhanced D1-like signaling system within the NAc and since this system is antagonistic to partner preference formation, we next tested if this neural restructuring is responsible for pair bond maintenance.

\section{NEURAL REORGANIZATION WITHIN THE NAC UNDERLIES PAIR BOND MAINTENANCE}

Given that pair bonded animals have increased D1-like receptor expression within the NAc and show high levels of aggression toward novel females, we tested if this neural restructuring was associated with increased aggression. Specifically, we used a resident-intruder test to determine if up-regulation of D1-like receptors within the NAc mediates the aggressive rejection of potentially new mates, i.e. selective aggression (Gobrogge et al., 2007; Wang et al., 1997; Winslow et al., 1993). In this test, the female partner was removed from the home cage and both affiliative (Figure 5A) and aggressive (Figure 5B) behavior of the male subject was examined following introduction of an 'intruder' female (Wang et al., 1997; Winslow et al., 1993). Pair bonded males showed significantly higher levels of affiliative behavior toward their familiar partners compared to that shown by sexually naive males presented with a novel female (Figure 5C). While pair bonded males show almost no affiliative behavior toward novel females (strangers) (Figure 5C), affiliative behavior is returned to levels expressed by sexually naive subjects if either D2 or D1-like receptors were blocked within the NAc (Figure 5B).

Neither sexually naive males presented with a novel female nor pair bonded males presented with their partner showed aggressive behavior (Figure 5D). However, pair bonded males were extremely aggressive when presented with novel females (strangers), showing a significant increase in the numbers of attacks (Figure 5D). Aggressive behavior was abolished by blockade of D1-like (but not D2-like) receptors within the NAc (Figure 5D). These data show that the up-regulation of D1-like receptors described above (Figure 4) mediates selective aggression. Thus, plasticity within the mesolimbic DA system underlies the decision to reject potentially new mates and thus maintains the initial pair bond.

\section{SUMMARY OF DOPAMINE REGULATION OVER PAIR BOND FORMATION AND MAINTENANCE}

Mesolimbic DA regulation of pair bonding may have implications for cognitive and psychological processes associated with social choice and decision-making. DA transmission that mediates partner preference formation occurs specifically within the rostral portion of the NAc shell (Aragona et al., 2006) (Figure 6A). This sub-region is critical for processing positive affect and unconditioned aspects of associative learning (Di Chiara and Bassareo, 2007; Ikemoto, 2007; Pecina et al., 2006). Thus, DA transmission within the NAc shell may regulate partner preference formation through enhanced reward processing or incentive motivation (Berridge, 2007; Di Chiara and Bassareo, 2007). Additionally, DA transmission within the NAc shell is also important for mother-offspring bonds, which is an inherently rewarding social attachment (Champagne et al., 2004; Li and Fleming, 2003; Numan et al., 2005). Together,

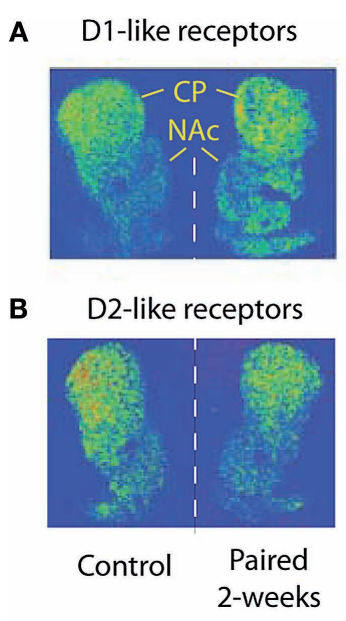

FIGURE 4 | Up-regulation of D1-like receptors within the NAc of pair bonded animals. (A) Representative examples of D1-like receptor binding within the dorsal and ventral striatum of sexually naive adult male prairie voles (left) and pair bonded males (paired with a female for 2 weeks; right). (B) Representative examples for

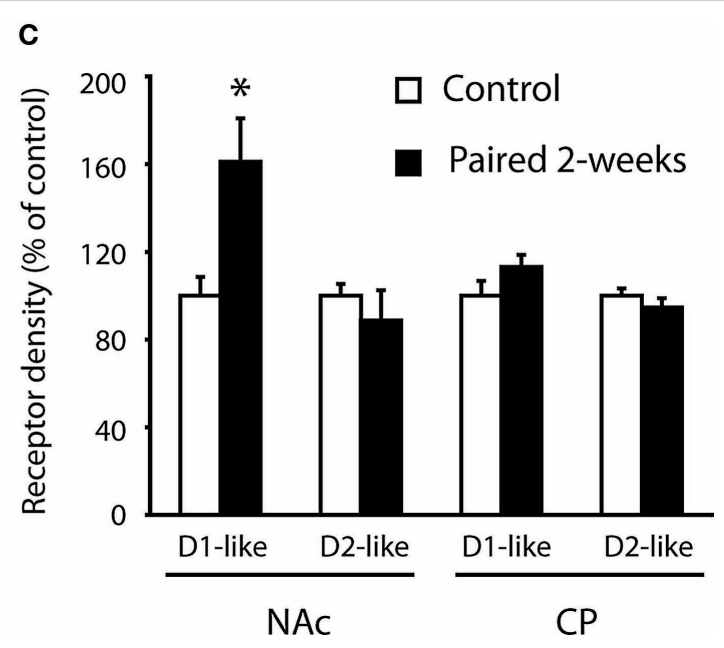

D2-like receptor binding. (C) Quantification of receptor binding expressed as percent of control subjects. Pair bonded males show a significant increase in D1-like receptor binding within the NAc but not the CP (caudate-putamen). There is no significant change in D2-like receptor binding within either striatal region. 
A
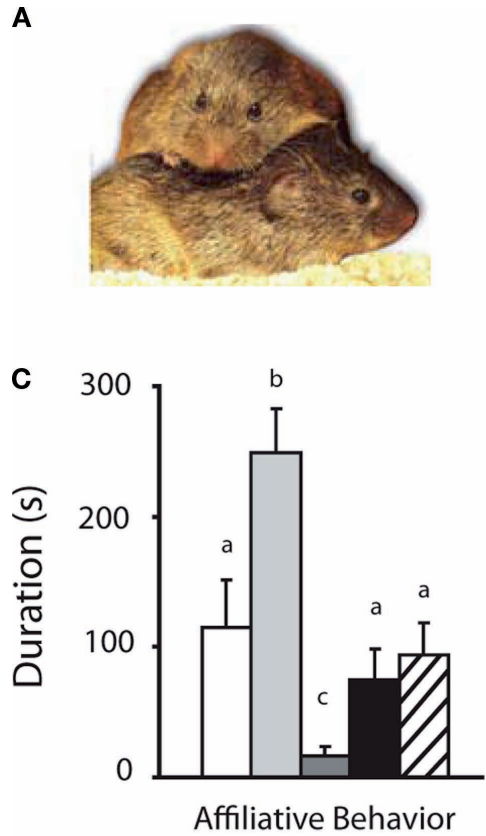

B

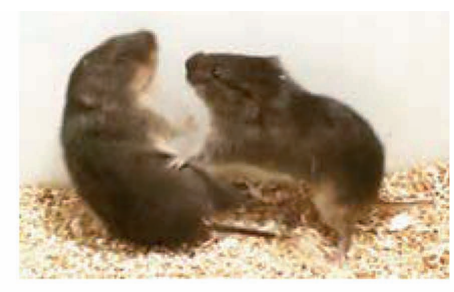

D

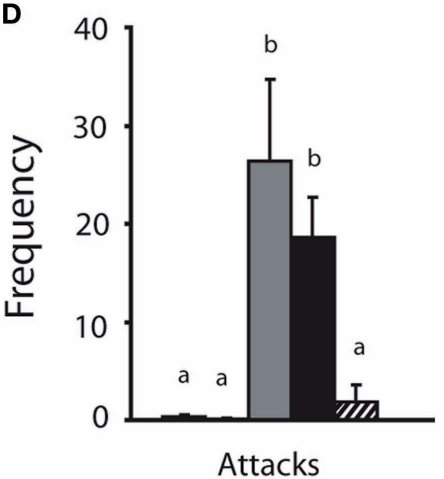

D2 ant + stranger

Z D1 ant + stranger
FIGURE 5 | Dopamine regulation of pair bond maintenance as indicated by selective aggression toward novel females. (A) Photo of pair bonded mates engaged in affiliative behavior (typically huddling or side-by-side contact). (B) Pair bonded male (right) showing aggressive behavior toward an unfamiliar/novel female (stranger; left). (C) Quantification of affiliative behavior during a 6-min resident intruder test of selective aggression. Pair bonded males show significantly more affiliative behavior than other group when presented with their familiar partner, but significantly less affiliation when presented with unfamiliar females (strangers). Blockade of either D1- or D2-like receptors restores affiliative behavior in pair bonded males to levels expressed by sexually naive males being exposed to a female for the first time. (D) While sexually naive (presented with a female) and pair bonded males (presented with their partners) show no aggressive behavior, pair bonded males show significantly greater levels of aggression when presented with a novel female (stranger). Selective aggression is blocked by D1-like (but not D2-like) receptors within the NAc. these data suggest that reward processing is a critical component of partner preference formation in prairie voles.

Within the NAc shell, DA regulation of partner preference formation is highly specific. Mating-induced DA release selectively activates D2-like receptors and decreases cAMP signaling to promote pair bond formation (Figure 6B). Conversely, activation of D1-like receptors and increased activation of cAMP signaling prevents pair bond formation (Figure 6C). These data indicate that, under natural circumstances, DA transmission is not uniformly increased as it is under certainly laboratory conditionings (Schultz, 2002). Rather, the pair bonding studies suggest that prairie vole social interactions result in modest increases in extracellular DA concentration that selectively activate high affinity D2-like receptors while not activating low affinity D1-like receptors (Richfield et al., 1989). However, it will be necessary for future studies to test this by measuring real-time DA transmission (Aragona et al., 2008; Day et al., 2007; Phillips et al., 2003) during prairie vole social interactions to determine if in vivo DA transmission is consistent with the behavioral pharmacology described in this review.

Compared to their basal state (Figure 6D), pair bonded males show a robust increase in the surface expression of D1-like receptors within the NAc (Figure 6E). We have suggested this may be a compensatory increase following the lack D1-like receptor activation during social interactions that promote pair bond formation (Aragona et al., 2006). Since pair bonded males show an up-regulation in D1-like receptors within the NAc and activation of these receptors prevents pair bond formation, we have suggested that when pair bonded males in their natural environment encounter a novel female, DA is released in very high concentration (Robinson et al., 2002) sufficient to activate low affinity D1-like receptors (Richfield et al., 1989), especially since there appear to be a greater number of antagonistic D1-like receptors in pair bonded voles. This promotes the aggressive rejection of potentially new mates and thus represents an elegant mechanism for maintenance of the initial pair bond. Taken together, these data demonstrate that DA transmission with the NAc differentially mediates initial partner preference formation and the subsequent rejection of potentially novel mates. This is achieved, at least in part, by neuroplasticity (up-regulation of D1-like receptors) within this mesolimbic DA signaling system. This represents a powerful example in which a complex monogamous social organization can be significantly accounted for by two rather straightforward choice behaviors that are both mediated by emotional/reward processing by mesolimbic DA signaling. 


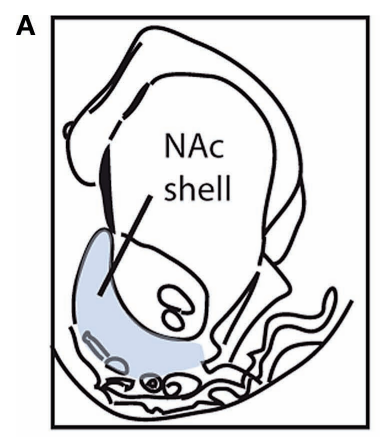

B

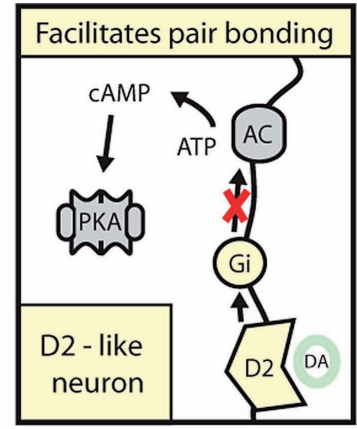

C

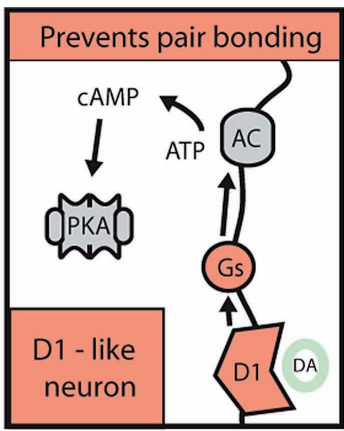

D Sexually Naive Male

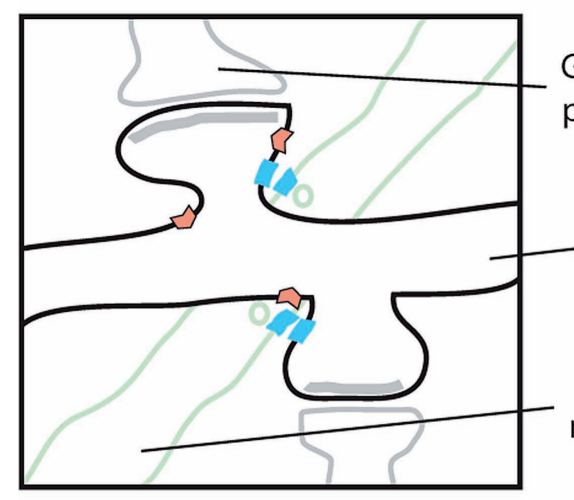

E

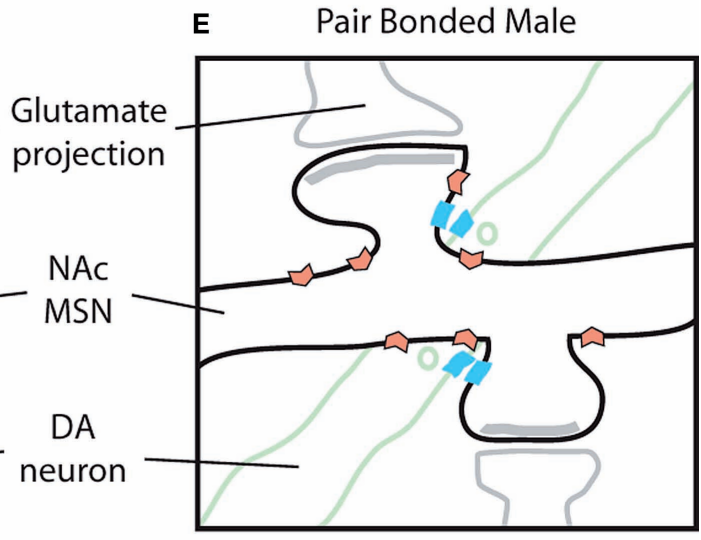

$=$ DA synapse
$=\mathrm{DA}$ vesicles
FIGURE 6 | Differential regulation of pair bond formation and maintenance by dopamine transmission within the NAc. (A) Cartoon based on (Arbuthnott and Wickens, 2007) showing the portion of the NAc shell where DA manipulations effect pair bond formation. (B) Diagram of D2-like signaling pathway involved in partner preference formation. (C) Diagram of D1-like signaling pathway that prevents partner preference formation. (D) Cartoon of medium spiny neuron (MSN) within the NAc receive glutamate projections to the heads of spines and dopaminergic projections to the neck of spines. This diagram represents D1-like receptor expression in sexually naive males. (E) A cartoon depicting the up-regulation of D1-like receptors in pair bonded male prairie voles.

\section{DOPAMINE-OXYTOCIN INTERACTIONS AND PARTNER PREFERENCE FORMATION}

Despite the critical role of DA in pair bonding, DA interacts with multiple neuropeptide systems in its regulation of this behavior (Lim et al., 2004b, 2007; Young and Wang, 2004). In particular, DA interactions with oxytocin receptors within the NAc are essential for pair bond formation (Liu and Wang, 2003). Activation of D2-like receptors within the NAc facilitates partner preference formation in the absence of mating, however, blockade of oxytocin receptors within this region (by co-infusion of an oxytocin receptor antagonist and a D2-like receptor agonist) prevents partner preferences induced by D2 activation (Liu and Wang, 2003). Further, facilitation of partner preference formation by activation of oxytocin receptors is not effective if D2like receptors are blocked (Liu and Wang, 2003). Importantly, this study was conducted in female prairie voles (Liu and Wang, 2003), however, we have also shown that oxytocin receptors within the NAc are critical for partner preference formation in males (M. Smeltzer and Z. Wang, unpublished observations). While the mechanism of DA-oxytocin interactions is unknown, selective lesions of dopaminergic terminals in prairie voles did not reduce oxytocin receptor expression within the NAc (Lim et al., 2004a). This indicates that oxytocin receptors in this region are postsynaptic. Further, since oxytocin and D2-like receptors are both coupled to inhibitory G-protein signaling molecules (Burns et al., 2001), activation of both types of receptors may facilitate partner preference formation by inhibition of cAMP signaling pathways (Aragona and Wang, 2007). While existing data suggest that pair bond formation is mediated by co-activation of both oxytocin and D2-like DA receptors (Gingrich et al., 2000; Liu and Wang, 2003; Young et al., 2001), it is possible that they represent parallel systems that co-exist within the NAc. Future studies are needed to understand if DA and oxytocin receptor systems directly interact, and if so, determine if these interactions occur on the same or connected cells. Still, additional studies are required to understand DA interactions with the signaling systems critical for pair bonding but located outside of the NAc (such as vasopressin within the ventral pallidum; Lim et al., 2004b). 


\section{COMPARISON BETWEEN NEURAL REGULATION OF SOCIAL REWARD IN PRAIRIE VOLES AND HUMANS}

Interestingly, the neural regulation of mate choice in humans also involves DA signaling systems (Fisher et al., 2005). Specifically, presentation of a picture of one's partner increases activation of dopaminergic circuitry in a similar manner as that caused by monetary reward (Aron et al., 2005; Zald et al., 2004). Thus, mate choice in humans may involve primary motivational or rewarding processes (Fisher et al., 2005) that are consistent with those observed in prairie voles. As such, the neural basis of partner preferences in prairie voles represents an excellent model for these aspects of mate choice in humans. Moreover, these findings suggest that understanding the neurobiology of reward processing is critical for understanding the neurobiology of social choice and decisionmaking (Loewenstein et al., 2008; Sanfey, 2007; Zak, 2004). Indeed, it has been suggested that pro-social behaviors may be achieved by activation of reward circuitry that promote cooperative behavior, in part, by facilitating positive emotions (Harbaugh et al., 2007), including feelings of trust (Rilling et al., 2002).

Trust is an essential component of human social organization and recent studies have shown that one neuropeptide critical for NAc regulation of pair bonding in voles, oxytocin, is critical for trust behavior in humans (Zak et al., 2004). The involvement of oxytocin in trust behavior was examined using a trust game, in which one player acts as an 'investor' that must choose whether or not to give money to a second player. If the 'investor' gives money to the second player, the amount of money in the game is increased and the 'investor' hopes that (during the second player's turn) the second player will reciprocate, giving the investor back more money than originally invested (Kosfeld et al., 2005). This is a one trial game so there is nothing to stop the second player from simply keeping all of the money. Thus, there is significant cost for the first player to trust that the second player will reciprocate. Interestingly, intra-nasal administration of oxytocin increased the ability of the 'investor' to overcome the risk associated with trust and increased the amount of money that the 'investor' gives to the second player (Kosfeld et al., 2005). Therefore, oxytocin appears to play a critical role in pro-social behavior in both humans and prairie voles.

\section{REFERENCES}

Aragona, B. J., Cleaveland, N. A., Stuber, G. D., Day, J. J., Carelli, R. M., and Wightman, R. M. (2008). Preferential enhancement of dopamine transmission within the nucleus accumbens shell by cocaine is attributable to a direct increase in phasic dopamine release events. J. Neurosci. 28, 8821-8831.

Aragona, B. J., Liu, Y., Curtis, J. T., Stephan, F. K., and Wang, Z. (2003). A critical role for nucleus accumbens dopamine in partner-preference formation in male prairie voles. J. Neurosci. 23, 3483-3490.

Aragona, B. J., Liu, Y., Yu, Y. J., Curtis, J. T., Detwiler,J.M., Insel, T.R., andWang, Z. (2006). Nucleus accumbens dopamine differentially mediates the formation and maintenance of monogamous pair bonds. Nat. Neurosci. 9, 133-139. prairie vole (Microtus ochrogaster): roendocrine research on pair bonding. ILAR J. 45, 35-45.

Aragona, B. J., and Wang, Z. (2007). Opposing regulation of pair bond formation by cAMP signaling within the nucleus accumbens shell. J. Neurosci. 27, 13352-13356.

Arbuthnott, G.W., and Wickens, J. (2007). Space, time and dopamine. Trends Neurosci. 30, 62-69.

Aron, A., Fisher, H., Mashek, D. J. Strong, G., Li, H., and Brown, L. L. (2005). Reward, motivation, and
Aragona, B. J., and Wang, Z. (2004). The an animal model for behavioral neu-

\section{CONCLUSION}

The current review emphasizes some striking similarities between the neurobiology underlying pro-social behaviors in humans and prairie voles. As such, the prairie vole model is likely to be a powerful tool to investigate the neural regulation of social choice in more invasive ways that are not possible when using human subjects. While the prairie vole field is still in its infancy, experiments using this species clearly demonstrate that mesolimbic DA transmission is essential for social choice. Given that this system mediates aspects of reward and emotional processing, its involvement in social decisionmaking among humans may explain why humans often display strong social preferences rather than always acting out of pure selfregard (Camerer and Fehr, 2006; Fehr and Camerer, 2007; Sanfey, 2007). As the field of social neuroeconomics advances, it continues to consider whether social decision-making is best conceptualized as rational decision-making that is complicated because it involves more than one agent and thus requires more sophisticated learning alorithms (Lee, 2008), or if it is more informative to regard social decision-making as largely guided by emotional social motivation and hedonic processing (Sanfey et al., 2003; Skuse and Gallagher, 2009). While social decision-making certainly involves both reasoning as well as emotional processing, data from the prairie vole model demonstrate how a complex social organization can be achieved by a relatively small number of rather simplistic choice behaviors that are significantly mediated by reward processing. This supports the view that selection favored organisms that dealt with complex decisions by acting according to the degree of pleasure or displeasure likely to be associated with their behavioral response (Cabanac et al., 2009). Thus, while brains appear to be capable of an impressive capacity for logic and reason, very complex phenomena, such as social decision-making and cognition, can be also be robustly explained by hedonic and emotional processing.

\section{ACKNOWLEDGEMENTS}

The authors wish to thank Shanna L. Harkey for photos and Jeremy H. Day, Joshua L. Jones, and Bobby W. Pastrami for reading the manuscript. This work was supported by National Institutes of Health grants MHR01-58616, DAR01-19627, and DAK02-23048 to ZXW.

emotion systems associated with early-stage intense romantic love. J. Neurophysiol. 94, 327-337.

Bales, K. L., Plotsky, P. M., Young, L. J., Lim, M. M., Grotte, N., Ferrer, E., and Carter, C.S. (2007). Neonatal oxytocin manipulations have long-lasting, sexually dimorphic effects on vasopressin receptors. Neuroscience 144, 38-45.

Bamshad, M., Novak, M. A., and de Vries, G. J. (1993). Sex and species differences in the vasopressin innervation of sexually naive and parental prairie voles, Microtus ochrogaster and meadow voles, Microtus pennsylvanicus. J. Neuroendocrinol. 5, 247-255.

Bamshad, M., Novak, M. A., and de Vries, G. J. (1994). Cohabitation alters vasopressin innervation and paternal behavior in prairie voles (Microtus ochrogaster). Physiol. Behav. 56, 751-758.

Becker, J. B., Rudick, C. N., and Jenkins, W. J. (2001). The role of dopamine in the nucleus accumbens and striatum during sexual behavior in the female rat. J. Neurosci. 21, 3236-3241.

Berridge, K. C. (2007). The debate over dopamine's role in reward: the case for incentive salience. Psychopharmacology (Berl.) 191, 391-431.

Berridge, K.C., and Robinson, T.E. (2003). Parsing reward. Trends Neurosci. 26, 507-513.

Burns, P. D., Mendes, J. O., Jr., Yemm, R. S. Clay, C. M., Nelson, S. E., Hayes, S. H., and Silvia, W. J. (2001). Cellular 
mechanisms by which oxytocin mediates ovine endometrial prostaglandin F2alpha synthesis: role of $\mathrm{G}(\mathrm{i})$ proteins and mitogen-activated protein kinases. Biol. Reprod. 65, 1150-1155.

Cabanac, M., Cabanac, A. J., and Parent, A. (2009). The emergence of consciousness in phylogeny. Behav. Brain Res. 198, 267-272.

Cacioppo, J. T., Berntson, G. G., Sheridan, J. F., and McClintock, M. K. (2000). Multilevel integrative analyses of human behavior: social neuroscience and the complementing nature of social and biological approaches. Psychol. Bull. 126, 829-843.

Camerer, C. F., and Fehr, E. (2006). When does "economic man" dominate social behavior? Science 311, 47-52.

Carter, C. S., DeVries, A. C., and Getz, L. L. (1995). Physiological substrates of mammalian monogamy: the prairie vole model. Neurosci. Biobehav. Rev. 19, 303-314.

Carter, C. S., and Getz, L. L. (1993). Monogamy and the prairie vole. Sci. Am. 268, 100-106.

Champagne, F. A., Chretien, P., Stevenson, C. W., Zhang, T. Y., Gratton, A., and Meaney, M. J. (2004). Variations in nucleus accumbens dopamine associated with individual differences in maternal behavior in the rat. J. Neurosci. 24, 4113-4123.

Cho, M. M., DeVries, A. C., Williams, J. R., and Carter, C.S. (1999). The effects of oxytocin and vasopressin on partner preferences in male and female prairie voles (Microtus ochrogaster). Behav. Neurosci. 113, 1071-1079.

Curtis, J. T., and Wang, Z. (2005). Ventral tegmental area involvement in pair bonding in male prairie voles. Physiol. Behav. 86, 338-346.

Cushing, B. S., Martin, J. O., Young, L. J., and Carter, C.S. (2001). The effects of peptides on partner preference formation are predicted by habitat in prairie voles. Horm. Behav. 39, 48-58.

Cushing, B. S., and Wynne-Edwards, K. E. (2006). Estrogen receptor-alpha distribution in male rodents is associated with social organization. J. Comp. Neurol. 494, 595-605.

Day, J. J., Roitman, M. F., Wightman, R. M., and Carelli, R. M. (2007). Associative learning mediates dynamic shifts in dopamine signaling in the nucleus accumbens. Nat. Neurosci. 10, 1020-1028.

DeVries, A.C., DeVries, M. B., Taymans, S., and Carter, C. S. (1995). Modulation of pair bonding in female prairie voles (Microtus ochrogaster) by corticosterone. Proc. Natl. Acad. Sci. U.S.A. 92, 7744-7748.

DeVries, A. C., DeVries, M. B., Taymans, S. E., and Carter, C. S.
(1996). The effects of stress on social preferences are sexually dimorphic in prairie voles. Proc. Natl. Acad. Sci. U.S.A. 93, 11980-11984.

Dewsbury, D. A. (1975). Diversity and adaptation in rodent copulatory behavior. Science 190, 947-954.

Dewsbury, D.A. (1987). The comparative psychology of monogamy. Nebr. Symp. Motiv. 35, 1-50.

Di Chiara, G., and Bassareo, V. (2007) Reward system and addiction: what dopamine does and doesn't do. Curr. Opin. Pharmacol. 7, 69-76.

Emlen, S. T., and Oring, L. W. (1977). Ecology, sexual selection, and the evolution of mating systems. Science 197, 215-223.

Everitt, B. J., and Robbins, T. W. (2005). Neural systems of reinforcement for drug addiction: from actions to habits to compulsion. Nat. Neurosci. 8, 1481-1489.

Fehr, E., and Camerer, C. F. (2007). Social neuroeconomics: the neural circuitry of social preferences. Trends Cogn. Sci. 11, 419-427.

Fiorino, D. F., Coury, A., and Phillips, A. G. (1997). Dynamic changes in nucleus accumbens dopamine efflux during the Coolidge effect in male rats. J. Neurosci. 17, 4849-4855.

Fisher, H., Aron, A., and Brown, L. L. (2005). Romantic love: an fMRI study of a neural mechanism for mate choice. J. Comp. Neurol. 493, 58-62.

Fowler, C. D., Liu, Y., Ouimet, C., and Wang, Z. (2002). The effects of social environment on adult neurogenesis in the female prairie vole. J. Neurobiol. 51, 115-128.

Getz, L. L. (1978). Speculation on social structure and population cycles of microtine rodents. Biologist 60, 134-147.

Getz, L. L., and Carter, C. S. (1996). Prairie-vole partnerships. Am. Sci. 84, 56-62.

Getz, L. L., Carter, C. S., and Gavish, L. (1981). The mating system of the prairie vole, Microtus ochrogaster. field and laboratory evidence for pair-bonding. Behav. Ecol. Sociobiol. 8, 189-194.

Getz, L. L., and Hofmann, J. E. (1986). Social organization in free-living prairie voles, Microtus ochrogaster. Behav. Ecol. Sociobiol. 18, 275-282.

Gingrich, B., Liu, Y., Cascio, C., Wang, Z., and Insel, T. R. (2000). Dopamine D2 receptors in the nucleus accumbens are important for social attachment in female prairie voles (Microtus ochrogaster). Behav. Neurosci. 114, 173-183.

Gobrogge, K. L.,Liu, Y., Jia,X., and Wang, Z. (2007). Anterior hypothalamic neural activation and neurochemical associations with aggression in pair-bonded male prairie voles. J. Comp. Neurol. 502, 1109-1122.

Gray, G. D., and Dewsbury, D. A. (1973) A quantitative description of copulatory behavior in prairie voles (Microtus ochrogaster). Brain Behav. Evol. 8, 426-452.

Hall, E. R. (1981). The mammals of North America. New York, John Wiley.

Hammock, E. A., and Young, L. J. (2005). Microsatellite instability generates diversity in brain and sociobehavioral traits. Science 308, 1630-1634.

Harbaugh, W. T., Mayr, U., and Burghart, D. R. (2007). Neural responses to taxation and voluntary giving reveal motives for charitable donations. Science 316, 1622-1625.

Hoffmann, R. S., and Koeppl, J.W. (1985) Zoogeography. In Biology of New World Microtus, Vol. 8, R. H. Tamarin, ed. (Special Publication, American Society of Mammalogists), pp. 84-113.

Ikemoto, S. (2007). Dopamine reward circuitry: two projection systems from the ventral midbrain to the nucleus accumbens-olfactory tubercle complex. Brain Res. Rev. 56, 27-78.

Insel, T. R., and Hulihan, T. J. (1995) A gender-specific mechanism for pair bonding: oxytocin and partner preference formation in monogamous voles. Behav. Neurosci. 109, 782-789.

Insel, T. R., and Shapiro, L. E. (1992). Oxytocin receptor distribution reflects social organization in monogamous and polygamous voles. Proc. Natl. Acad. Sci. U.S.A. 89, 5981-5985.

Insel, T. R., and Young, L. J. (2001). The neurobiology of attachment. Nat. Rev. Neurosci. 2, 129-136.

Jansson, A., Goldstein, M., Tinner, B., Zoli, M., Meador-Woodruff, J. H., Lew, J. Y., Levey, A. I., Watson, S., Agnati, L. F., and Fuxe, K. (1999). On the distribution patterns of D1, D2, tyrosine hydroxylase and dopamine transporter immunoreactivities in the ventral striatum of the rat. Neuroscience 89, 473-489.

Kelley, A. E. (2004). Memory and addiction: shared neural circuitry and molecular mechanisms. Neuron 44 161-179.

Kleiman, D. G. (1977). Monogamy in mammals. Q. Rev. Biol. 52, 39-69.

Kosfeld, M., Heinrichs, M., Zak, P. J., Fischbacher, U., and Fehr, E. (2005). Oxytocin increases trust in humans. Nature 435, 673-676.

Krueger, F., McCabe, K., Moll, J., Kriegeskorte, N., Zahn, R., Strenziok, M., Heinecke, A., and Grafman, J. (2007). Neural correlates of trust. Proc. Natl. Acad. Sci. U.S.A. 104, 20084-20089.
Lee, D. (2008). Game theory and neural basis of social decision making. Nat. Neurosci. 11, 404-409.

Li, M., and Fleming, A. S. (2003). Differential involvement of nucleus accumbens shell and core subregions in maternal memory in postpartum female rats. Behav. Neurosci. 117, 426-445.

Lim, M. M., Liu, Y., Ryabinin, A. E., Bai, Y., Wang, Z., and Young, L. J. (2007). CRF receptors in the nucleus accumbens modulate partner preference in prairie voles. Horm. Behav. 51, 508-515.

Lim, M.M., Murphy, A.Z., and Young, L. J. (2004a). Ventral striatopallidal oxytocin and vasopressin V1a receptors in the monogamous prairie vole (Microtus ochrogaster). J. Comp. Neurol. 468, 555-570.

Lim, M. M., Wang, Z., Olazabal, D. E., Ren, X., Terwilliger, E. F., and Young, L. J. (2004b). Enhanced partner preference in a promiscuous species by manipulating the expression of a single gene. Nature 429, 754-757.

Lim, M. M., and Young, L. J. (2004). Vasopressin-dependent neural circuits underlying pair bond formation in the monogamous prairie vole. Neuroscience 125, 35-45.

Liu, Y., Curtis, J. T., and Wang, Z. (2001). Vasopressin in the lateral septum regulates pair bond formation in male prairie voles (Microtus ochrogaster). Behav. Neurosci. 115, 910-919.

Liu, Y., and Wang, Z. X. (2003). Nucleus accumbens oxytocin and dopamine interact to regulate pair bond formation in female prairie voles. Neuroscience 121, 537-544.

Loewenstein, G., Rick, S., and Cohen, J. D. (2008). Neuroeconomics. Annu. Rev. Psychol. 59, 647-672.

Lynch, W. J., and Taylor, J. R. (2005). Persistent changes in motivation to self-administer cocaine following modulation of cyclic AMP-dependent protein kinase $\mathrm{A}$ (PKA) activity in the nucleus accumbens. Eur. J. Neurosci. 22, 1214-1220.

McGuire, B., Getz, L. L., Hofmann, J. E., Pizzuto, T., and Frase, B. (1993). Natal dispersal and philopatry in prairie voles (Microtus ochrogaster) in relation to population density, season, and natal social environment. Behav. Ecol. Sociobiol. 32, 293-302.

McGuire, B., and Novak, M. (1984). A comparison of maternal behaviour in the meadow vole (Microtus pennsylvanicus), prairie vole (M. ochrogaster) and pine vole (M. pinetorum). Anim. Behav. 32, 1132-1141.

McGuire, B., Russell, K. D., Mahoney, T., and Novak, M. (1992). The effects of mate removal on pregnancy success in prairie voles (Microtus ochrogaster) 
and meadow voles (Microtus pennsylvanicus). Biol. Reprod. 47, 37-42.

Missale, C., Nash, S. R., Robinson, S. W., Jaber, M., and Caron, M. G. (1998). Dopamine receptors: from structure to function. Physiol. Rev. 78, 189-225.

Neve, K.A., Seamans, J.K., and TranthamDavidson, H. (2004). Dopamine receptor signaling. J. Recept. Signal. Transduct. Res. 24, 165-205.

Numan, M., Numan, M. J., Pliakou, N., Stolzenberg, D. S., Mullins, O. J., Murphy, J.M., and Smith, C. D. (2005). The effects of D1 or D2 dopamine receptor antagonism in the medial preoptic area, ventral pallidum, or nucleus accumbens on the maternal retrieval response and other aspects of maternal behavior in rats. Behav. Neurosci. 119, 1588-1604.

Oliveras, D., and Novak, M. (1986). A comparison of paternal behaviour in the meadow vole Microtus pennsylvanicus, the pine vole M. pinetorum and the prairie vole M. ochrogaster. Anim. Behav. 34, 519-526.

Pecina, S., Smith, K. S., and Berridge, K.C. (2006). Hedonic hot spots in the brain. Neuroscientist 12, 500-511.

Pfaus, J. G., Damsma, G., Wenkstern, D., and Fibiger, H.C. (1995). Sexual activity increases dopamine transmission in the nucleus accumbens and striatum of female rats. Brain Res. 693, 21-30.

Pfeiffer, T., Rutte, C., Killingback, T., Taborsky, M., and Bonhoeffer, S. (2005). Evolution of cooperation by generalized reciprocity. Proc. Biol. Sci. 272, 1115-1120.

Phillips, P. E., Stuber, G. D., Heien, M. L., Wightman, R. M., and Carelli, R. M. (2003). Subsecond dopamine release promotes cocaine seeking. Nature 422 , 614-618.

Phillips, P. E., Walton, M. E., and Jhou, T. C. (2007). Calculating utility: preclinical evidence for cost-benefit analysis by mesolimbic dopamine. Psychopharmacology (Berl.) 191, 483-495.

Richfield, E. K., Penney, J. B., and Young, A. B. (1989). Anatomical and affinity state comparisons between dopamine D1 and D2 receptors in the rat central nervous system. Neuroscience 30, 767-777.
Rilling,J., Gutman,D.,Zeh, T., Pagnoni, G., Berns, G., and Kilts, C. (2002). A neural basis for social cooperation. Neuron 35, 395-405.

Robinson, D. L., Heien, M. L., and Wightman, R. M. (2002). Frequency of dopamine concentration transients increases in dorsal and ventral striatum of male rats during introduction of conspecifics. J. Neurosci. 22, 10477-10486.

Roitman, M. F., Wheeler, R. A., and Carelli, R. M. (2005). Nucleus accumbens neurons are innately tuned for rewarding and aversive taste stimuli, encode their predictors, and are linked to motor output. Neuron 45, 587-597.

Roitman, M. F., Wheeler, R. A., Wightman, R. M., and Carelli, R. M. (2008). Real-time chemical responses in the nucleus accumbens differentiate rewarding and aversive stimuli. Nat. Neurosci. 11, 1376-1377.

Rutte, C., and Taborsky, M. (2007). Generalized Reciprocity in Rats. PLoS Biol. 5, e196.

Salamone, J. D., and Correa, M. (2002). Motivational views of reinforcement: implications for understanding the behavioral functions of nucleus accumbens dopamine. Behav. Brain Res. 137, 3-25.

Sanfey, A. G. (2007). Social decisionmaking: insights from game theory and neuroscience. Science 318, 598-602.

Sanfey, A. G., Rilling, J. K., Aronson, J. A., Nystrom, L. E., and Cohen, J. D. (2003). The neural basis of economic decision-making in the ultimatum game. Science 300, 1755-1758.

Schultz, W. (2002). Getting formal with dopamine and reward. Neuron 36, 241-263.

Self, D. W., Genova, L. M., Hope, B. T., Barnhart, W. J., Spencer, J. J., and Nestler, E. J. (1998). Involvement of cAMP-dependent protein kinase in the nucleus accumbens in cocaine self-administration and relapse of cocaine-seeking behavior. J. Neurosci. $18,1848-1859$.

Skuse, D. H., and Gallagher, L. (2009). Dopaminergic-neuropeptide interactions in the social brain. Trends $\operatorname{Cog} n$. Sci. 13, 27-35.
Tankersley, D., Stowe, C. J., and Huettel, S. A. (2007). Altruism is associated with an increased neural response to agency. Nat. Neurosci. 10, 150-151.

Thomas, J. A., and Birney, E. C. (1979). Parental care and mating system of the prairie vole, Microtus ochrogaster. Behav. Ecol. Sociobiol. 5, 171-186.

Thomas, S. A., and Wolff, J. O. (2004). Pair bonding and "the widow effect" in female prairie voles. Behav. Processes $67,47-54$.

Trivers, R. L. (1971). The evolution of reciprocal altruism. Q. Rev. Biol. 46, 35-57.

Wang, Z., Hulihan, T. J., and Insel, T. R. (1997). Sexual and social experience is associated with different patterns of behavior and neural activation in male prairie voles. Brain Res. 767, 321-332.

Wang, Z., Yu, G., Cascio, C., Liu, Y., Gingrich, B., and Insel, T. R. (1999). Dopamine D2 receptor-mediated regulation of partner preferences in female prairie voles (Microtus ochrogaster): a mechanism for pair bonding? Behav Neurosci. 113, 602-611.

Wang, Z. X., and Aragona, B. J. (2004) Neurochemical regulation of pair bonding in male prairie voles. Physiol. Behav. 83, 319-328.

Wang, Z. X., and Novak, M. (1992). Influence of the social environment on parental behavior and pup development of meadow voles (Microtus pennsylvanicus) and prairie voles (M. ochrogaster). J. Comp. Psychol. 106, 163-171.

Wheeler, R. A., Twining, R. C., Jones, J. L., Slater, J. M., Grigson, P. S., and Carelli, R. M. (2008). Behavioral and electrophysiological indices of negative affect predict cocaine selfadministration. Neuron 57, 774-785.

Williams, J. R., Catania, K. C., and Carter, C. S. (1992). Development of partner preferences in female prairie voles (Microtus ochrogaster): the role of social and sexual experience. Horm. Behav. 26, 339-349.

Winslow, J. T., Hastings, N., Carter, C. S., Harbaugh, C. R., and Insel, T. R. (1993). A role for central vasopressin in pair bonding in monogamous prairie voles. Nature 365, 545-548.
Wise, R. A. (2004). Dopamine, learning and motivation. Nat. Rev. Neurosci. 5, 483-494.

Witt, D. M., Carter, C. S., and Insel, T. R. (1991). Oxytocin receptor binding in female prairie voles: endogenous and exogenous oestradiol stimulation. J. Neuroendocrinol. 3, 155-161.

Witt,D.M.,Carter, C.S., andWalton, D. M. (1990). Central and peripheral effects of oxytocin administration in prairie voles (Microtus ochrogaster). Pharmacol. Biochem. Behav. 37, 63-69.

Young, L. J., Lim, M. M., Gingrich, B., and Insel, T. R. (2001). Cellular mechanisms of social attachment. Horm. Behav. 40, 133-138.

Young, L. J., and Wang, Z. (2004). The neurobiology of pair bonding. Nat. Neurosci. 7, 1048-1054.

Zak, P. J. (2004). Neuroeconomics. Philos. Trans. R. Soc. Lond., B, Biol. Sci. 359, 1737-1748.

Zak, P. J., Kurzban, R., and Matzner, W. T. (2004). The neurobiology of trust. Ann. N. Y. Acad. Sci. 1032, 224-227.

Zald, D. H., Boileau, I., El-Dearedy, W., Gunn, R., McGlone, F., Dichter, G. S., and Dagher, A. (2004). Dopamine transmission in the human striatum during monetary reward tasks. J. Neurosci. 24, 4105-4112.

Conflict of Interest Statement: The authors declare that the research was conducted in the absence of any commercial or financial relationships that could be construed as a potential conflict of interest.

Received: 23 April 2009; paper pending published: 15 May 2009; accepted: 23 July 2009; published online: 11 August 2009. Citation: Aragona BJ and Wang $Z$ (2009) Dopamine regulation of social choice in a monogamous rodent species. Front. Behav. Neurosci. 3:15. doi: 10.3389/neuro.08.015.2009

Copyright @ 2009 Aragona and Wang. This is an open-access article subject to an exclusive license agreement between the authors and the Frontiers Research Foundation, which permits unrestricted use, distribution, and reproduction in any medium, provided the original authors and source are credited. 